\title{
Effect of Processing Parameters and Temperature on Sliding Wear of H62 Copper Alloy Modified by Friction Stir Surface Processing
}

\author{
Weiwei SONG ${ }^{1,2,4 *}$, Xiaojing XU ${ }^{1}$, Dunwen ZUO $^{3}$, Jianli WANG ${ }^{2}$, Gang WANG ${ }^{4}$ \\ ${ }^{1}$ School of Mechanical Engineering, Jiangsu University, Zhenjiang 212013, China \\ ${ }^{2}$ College of Mechanical and Electrical Engineering, Huangshan University, Huangshan 245041, China \\ ${ }^{3}$ College of Mechanical and Electrical Engineering, Nanjing University of Aeronautics and Astronautics, Nanjing 210016, \\ China \\ ${ }^{4}$ School of Mechanical and Automotive Engineering, Anhui Polytechnic University, Wuhu 241000, China \\ crossref http://dx.doi.org/10.5755/j01.ms.23.3.16322
}

Received 30 September 2016; accepted 14 February 2017

\begin{abstract}
H62 copper alloy surface was modified by friction stir surface processing (FSSP) with different processing parameters including rotation rate, penetration depth and processing speed of the stirring tool under the room temperature $\left(25^{\circ} \mathrm{C}\right)$. Then friction and wear experiments of the surface were carried on at different temperatures. The experimental results show that (i) the specimens hardness initially increases with increasing the wear test temperature, then decreases with further increasing the temperature for fixed rotation rate and penetration depth, (ii) the wear resistances of the specimens decrease as the rotation rate of the stirring tool increases for fixed penetration depth and wear test temperature, (iii) the wear resistances of the specimens decrease as the penetration depth increases for constant rotation rate and wear test temperature. It is found that the optimal processing parameters are rotational speed $1200 \mathrm{rpm}$, temperature $100{ }^{\circ} \mathrm{C}$ and penetration depth $0.2 \mathrm{~mm}$, respectively, which can greatly improve the wear performance of the H62 surface. Therefore, FSSP is a promising technique for modifying H62 copper alloy, which can be widely applied in ship manufacturing. Keywords: friction stir surface processing, wear resistance, copper alloy, hardness, microstructure.
\end{abstract}

\section{INTRODUCTION}

Copper alloys have good mechanical properties, such as good plasticity at low as well as at high temperatures, and good machinability [1-4], which has attracted increasing attention for applying in ship manufacturing. The alloys are often used in high temperature environments, where the high temperature wear can adversely affect the service life of the parts made of the copper alloys, thus greatly hindering their further and extensive applications. Therefore, the surfaces of the copper alloys need to be processed to improve their high temperature wear resistance.

There are many methods for improving the high temperature wear resistance of copper alloys, such as shot peening, ion implantation, etc. However, the wear-resistant surface thickness achieved by these methods is only a few microns, which limits the useful lifetime of the workpiece.

Friction stir surface processing (FSSP) is a solid state processing method based on the friction stir welding process [5-9] In recent years, extensive research efforts have been undertaken to perform improvements in aluminum and magnesium alloys by FSSP $[10-12]^{1}$. These studies have found that the FSSP is an effective method to attain a uniform microstructure with grain refinement on the alloys surface.

However, so far little work has been done to improve high temperature wear resistance of copper alloys using FSSP technique. Therefore, in this work, H62 copper alloy surface is modified by FSSP with different processing

\footnotetext{
* Corresponding author. Tel.: +86-15955902779.

E-mail address: sww_2011@163.com (W. Song)
}

parameters, and the influence of the FSSP parameters and wear test temperature on the surface wear resistance are discussed. The results show that the FSSP is a promising solution to enhance surface hardening of the copper alloys.

\section{EXPERIMENTAL PROCEDURE}

An H62 copper alloy plate of thickness $10 \mathrm{~mm}$ was used for the FSSP experiments. The main chemical composition (wt.\%) of the $\mathrm{H} 62$ alloy is as follows: $\mathrm{Cu} 62.7 \%, \quad \mathrm{Fe} 0.15 \%, \quad \mathrm{~Pb} 0.08 \%, \quad \mathrm{Sb} 0.005 \%$, Bi $0.002 \%$, P $0.01 \%$, Zn $35.6 \%$, and other impurities accounting for the rest. The model of the friction stir welding machine used in the experiments is FSW-LMA10, and without needle of the stirring tool with $20 \mathrm{~mm}$ diameter as processing tool for copper alloy FSSP. The values of the FSSP parameters used in this work were as follows - the rotation rates (rotational speed) of the stirring tool: $800 \mathrm{rpm}, 1000 \mathrm{rpm}$ and $1200 \mathrm{rpm}$; and the penetration depth of the stirring tool: $0.1 \mathrm{~mm}, 0.15 \mathrm{~mm}$ and $0.2 \mathrm{~mm}$; the processing speed of the stirring tool was $150 \mathrm{~mm} / \mathrm{min}$. The FSSP test was done at the room temperature $\left(25^{\circ} \mathrm{C}\right)$. The corresponding specimens were obtained by the above processing parameters. Friction and wear test specimens of $30 \times 10 \times 5 \mathrm{~mm}$ were cut by a linear cutting machine along the vertical direction of the FSSP surface. The specimens were ground by a metallographic sandpaper. Subsequently, the specimen surface was cleaned, and polished to a mirror finish by a fabric pad. The HT-1000 high temperature friction and wear testing machine was employed as the test equipment. It was manufactured by the Lanzhou Institute of Chemical Physics, Chinese Academy of Sciences. The software of this device can obtain the real-time coefficient 
of friction during the test. The principle of operation is shown in Fig. 1.

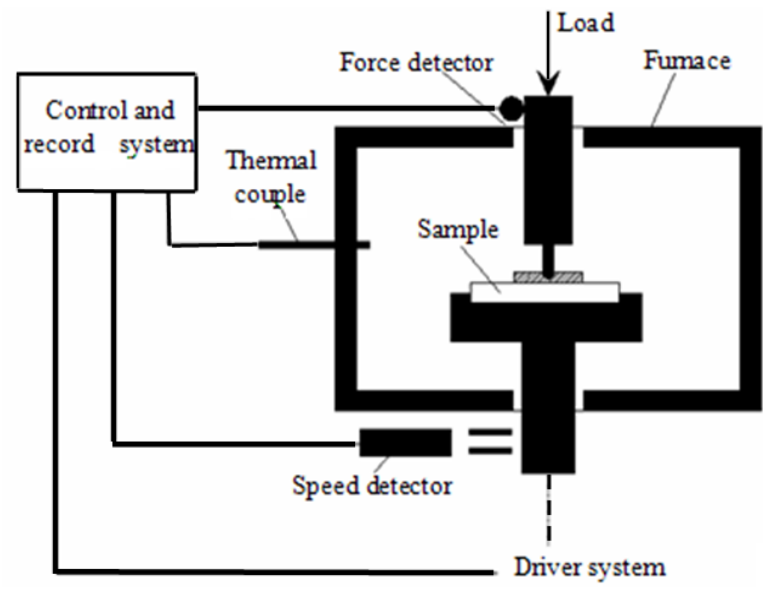

Fig. 1. The working principle of friction and wear test

The test specimen was fixed on the workbench, and the wear test was done using a steel ball of $3 \mathrm{~mm}$ diameter. This steel ball was made from the material GCr15 (high carbon chromium-bearing steel). For the friction experiments, the ball was pressed onto the sample attached to the workbench, which then revolved around an axis, while keeping the steel ball fixed. The speed of rotation was $560 \mathrm{rpm}$, the diameter of revolution circumscribed by the steel ball on the sample was $4 \mathrm{~mm}$, and the load of steel ball on the specimen was $350 \mathrm{~g}$. No lubrication was used during the testing process. The wear tests were conducted at the following temperatures: $25^{\circ} \mathrm{C}, 100{ }^{\circ} \mathrm{C}, 200{ }^{\circ} \mathrm{C}$, $400{ }^{\circ} \mathrm{C}$ and $500{ }^{\circ} \mathrm{C}$. The relative humidity in the test environment was $45 \% \pm 5 \%$. The friction and wear location was on the modified surface.

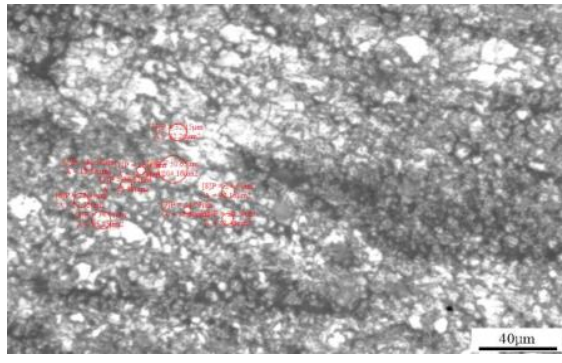

$\mathrm{a}-0.1 \mathrm{~mm}$

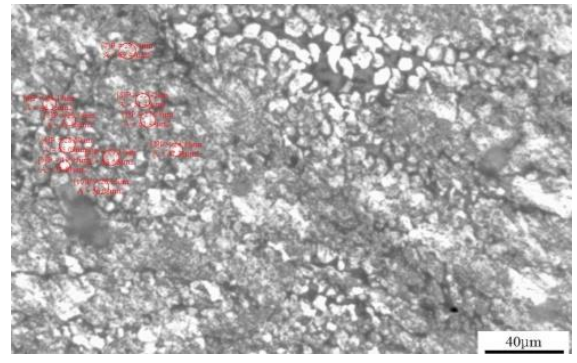

$\mathrm{b}-0.15 \mathrm{~mm}$

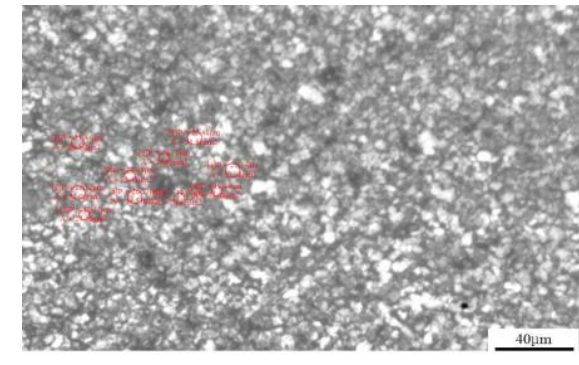

$\mathrm{c}-0.2 \mathrm{~mm}$

Fig. 2. The microstructure of modified surface of copper alloy subjected to FSSP with a stir tool rotational speed $800 \mathrm{rpm}$ for different penetration depths

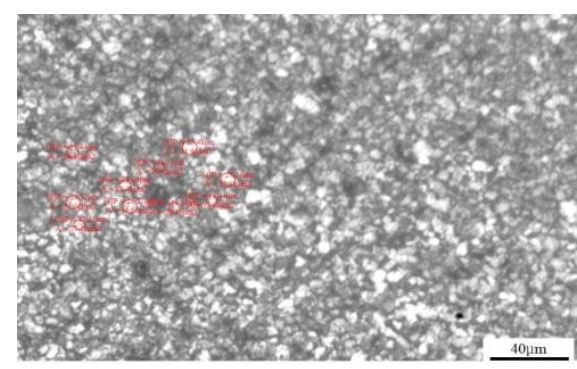

$\mathrm{a}-800 \mathrm{rpm}$

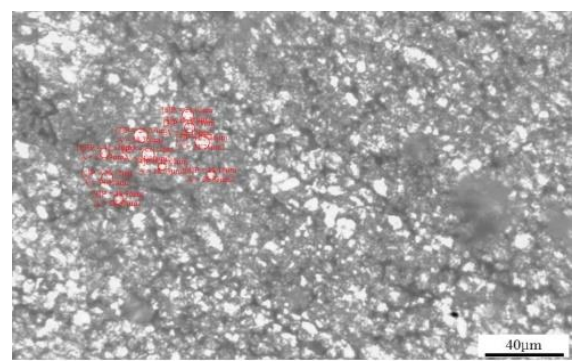

$\mathrm{b}-1000 \mathrm{rpm}$

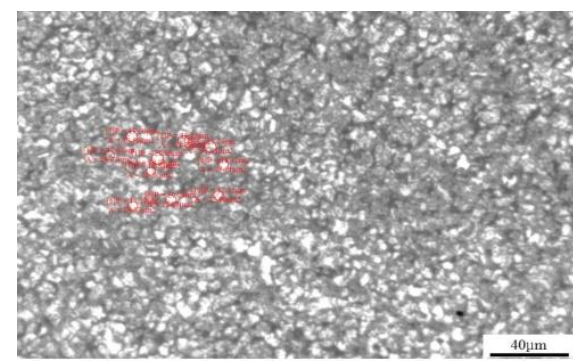

$\mathrm{c}-1200 \mathrm{rpm}$

Fig. 3. The microstructure of modified surface of copper alloy subjected to FSSP with a penetration depth of $0.2 \mathrm{~mm}$ for different rotational speeds 
The microstructure of the base metal is shown in Fig. 4. Thus, the grain size is smallest in the specimens which are subjected to the maximum rotation rate of the stirring tool, as well as the maximum penetration depth. As a result, the surface hardness is higher, the coefficient of friction and wearing capacity are smaller, similar to the works in Ref. [13] and [14]. This is also consistent with the previous analysis results.

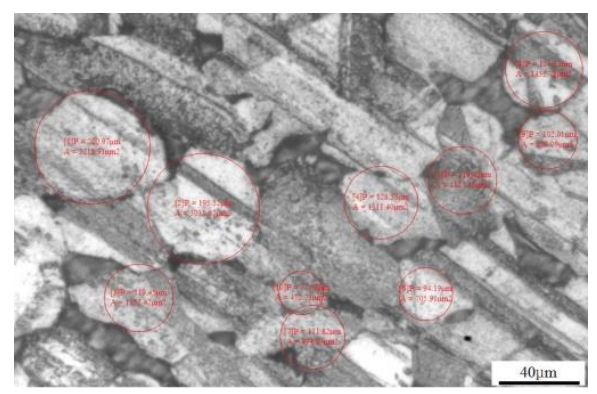

Fig. 4. The microstructure of the base metal

\subsection{Hardness}

The Rockwell hardness (the load is $980 \mathrm{~N}$ ) values of the specimens fabricated under different FSSP parameters and tested at various wear temperatures are listed in Table 1. It can be seen that the specimen hardness increases as the rotation rate of the stir tool increases with the constant penetration depth. The involved mechanisms lie in the fact that higher rotational speeds can cause higher temperatures to be generated within the workpiece, and facilitate grain refinement. The hardness also increases as the penetration depth increases with the fixed rotation rate of the stirring tool, which should be attributed to the fact that the increase of the penetration depth gives rise to the increase of the press which leads to the higher temperature. The specimen hardness initially increases with the increase of the wear test temperature, and then decreases as the wear temperature further increases with the fixed rotation rate and penetration depth. The main reason is as follows: the softening material of specimen surface is removed at $100{ }^{\circ} \mathrm{C}$, causing the hardness improvement of the modified surface; as the wear test temperature increases to $200{ }^{\circ} \mathrm{C}$, the modified surface undergoes recrystallization, resulting in the grain refinement; while when the temperature further increases to $500{ }^{\circ} \mathrm{C}$, the further grain growth gives rise to lower hardness [15].

\subsection{Friction and wear}

The influence of the FSSP parameters and wear test temperature on the wear resistance of specimen is also examined. The experimental results are listed in Table 2. From the Table 2, it can be seen that the wearing capacity of the specimen decreases as the rotation rate of the stirring tool increases for the fixed penetration depth and wear test temperature, and also decreases with the increase of the penetration depth of the stirring tool for the constant rotation speed and wear test temperature. The wearing capacity of the specimen initially increases with the increase of the wear test temperature, and then decreases with the further increase of the temperature for the fixed rotational speed and penetration depth. For different FSSP parameters, especially the process of the transformation from $400{ }^{\circ} \mathrm{C}$ to $500{ }^{\circ} \mathrm{C}$, the wear capacity of specimen is drastically changed.

Table 1. The hardness values under different FSSP parameters and wear temperature

\begin{tabular}{|c|c|c|c|c|c|c|c|c|c|c|c|c|c|c|c|}
\hline \multirow{3}{*}{$\begin{array}{c}\text { FSSP } \\
\text { parameters } \\
\text { Temperature }\end{array}$} & \multicolumn{15}{|c|}{$800 \mathrm{rpm}$ (rotational speed) } \\
\hline & \multicolumn{5}{|c|}{$0.1 \mathrm{~mm}$ (penetration depth) } & \multicolumn{5}{|c|}{$0.15 \mathrm{~mm}$ (penetration depth) } & \multicolumn{5}{|c|}{$0.2 \mathrm{~mm}$ (penetration depth) } \\
\hline & $25^{\circ} \mathrm{C}$ & $100^{\circ} \mathrm{C}$ & $200^{\circ} \mathrm{C}$ & $400^{\circ} \mathrm{C}$ & $500^{\circ} \mathrm{C}$ & $25^{\circ} \mathrm{C}$ & $100^{\circ} \mathrm{C}$ & $200^{\circ} \mathrm{C}$ & $400^{\circ} \mathrm{C}$ & $500^{\circ} \mathrm{C}$ & $25^{\circ} \mathrm{C}$ & $100^{\circ} \mathrm{C}$ & $200^{\circ} \mathrm{C}$ & $400^{\circ} \mathrm{C}$ & $500^{\circ} \mathrm{C}$ \\
\hline Hardness, HRB & 8.6 & 17.1 & 16.2 & 11.8 & 3.6 & 9 & 17.9 & 16.5 & 13 & 4.2 & 11.8 & 18.3 & 17.9 & 13.4 & 7.1 \\
\hline \multirow{2}{*}{$\begin{array}{c}\text { FSSP } \\
\text { parameters }\end{array}$} & \multicolumn{15}{|c|}{$1000 \mathrm{rpm}$ (rotational speed) } \\
\hline & \multicolumn{5}{|c|}{$0.1 \mathrm{~mm}$ (penetration depth) } & \multicolumn{5}{|c|}{$0.15 \mathrm{~mm}$ (penetration depth) } & \multicolumn{5}{|c|}{$0.2 \mathrm{~mm}$ (penetration depth) } \\
\hline Temperature & $25^{\circ} \mathrm{C}$ & $100^{\circ} \mathrm{C}$ & $200^{\circ} \mathrm{C}$ & $400^{\circ} \mathrm{C}$ & $500^{\circ} \mathrm{C}$ & $25^{\circ} \mathrm{C}$ & $100^{\circ} \mathrm{C}$ & $200^{\circ} \mathrm{C}$ & $400^{\circ} \mathrm{C}$ & $500^{\circ} \mathrm{C}$ & $25^{\circ} \mathrm{C}$ & $100^{\circ} \mathrm{C}$ & $200^{\circ} \mathrm{C}$ & $400^{\circ} \mathrm{C}$ & $500^{\circ} \mathrm{C}$ \\
\hline Hardness, HRB & 13.4 & 18.2 & 17 & 12.3 & 4.7 & 13.7 & 19.2 & 18.5 & 13 & 4.4 & 14 & 20.4 & 19.5 & 16.2 & 7.3 \\
\hline FSSP & \multicolumn{15}{|c|}{$1200 \mathrm{rpm}$ (rotational speed) } \\
\hline parameters & \multicolumn{5}{|c|}{$0.1 \mathrm{~mm}$ (penetration depth) } & \multicolumn{5}{|c|}{$0.15 \mathrm{~mm}$ (penetration depth) } & \multicolumn{5}{|c|}{$0.2 \mathrm{~mm}$ (Penetration depth) } \\
\hline Temperature & $25^{\circ} \mathrm{C}$ & $100^{\circ} \mathrm{C}$ & $200^{\circ} \mathrm{C}$ & $400^{\circ} \mathrm{C}$ & $500^{\circ} \mathrm{C}$ & $25^{\circ} \mathrm{C}$ & $100^{\circ} \mathrm{C}$ & $200^{\circ} \mathrm{C}$ & $400^{\circ} \mathrm{C}$ & $500^{\circ} \mathrm{C}$ & $25^{\circ} \mathrm{C}$ & $100^{\circ} \mathrm{C}$ & $200^{\circ} \mathrm{C}$ & $400^{\circ} \mathrm{C}$ & $500^{\circ} \mathrm{C}$ \\
\hline Hardness, HRB & 14.2 & 18.3 & 19.1 & 12.7 & 5.1 & 15.1 & 19.6 & 20.4 & 13.6 & 6.5 & 18.9 & 24.4 & 22.5 & 18.1 & 8.1 \\
\hline
\end{tabular}

Table 2. The wearing capacity for different FSSP parameters and wear test temperatures

\begin{tabular}{|c|c|c|c|c|c|c|c|c|c|c|c|c|c|c|c|}
\hline \multirow{2}{*}{$\begin{array}{c}\text { FSSP } \\
\text { parameters }\end{array}$} & \multicolumn{15}{|c|}{$800 \mathrm{rpm}$ (rotational speed) } \\
\hline & \multicolumn{5}{|c|}{$0.1 \mathrm{~mm}$ (penetration depth) } & \multicolumn{5}{|c|}{$0.15 \mathrm{~mm}$ (penetration depth) } & \multicolumn{5}{|c|}{$0.2 \mathrm{~mm}$ (penetration depth) } \\
\hline Temperature & $25^{\circ} \mathrm{C}$ & $100^{\circ} \mathrm{C}$ & $200^{\circ} \mathrm{C}$ & $400^{\circ} \mathrm{C}$ & $500^{\circ} \mathrm{C}$ & $25^{\circ} \mathrm{C}$ & $100^{\circ} \mathrm{C}$ & $200^{\circ} \mathrm{C}$ & $400^{\circ} \mathrm{C}$ & $500^{\circ} \mathrm{C}$ & $25^{\circ} \mathrm{C}$ & $100^{\circ} \mathrm{C}$ & $200^{\circ} \mathrm{C}$ & $400^{\circ} \mathrm{C}$ & $500^{\circ} \mathrm{C}$ \\
\hline $\begin{array}{c}\text { Wearing } \\
\text { capacity, } \mathrm{mm}^{3}\end{array}$ & 0.0805 & 0.0347 & 0.0534 & 0.0799 & 0.4440 & 0.0533 & 0.0332 & 0.0489 & 0.0796 & 0.4463 & 0.0498 & 0.0208 & 0.0375 & 0.0545 & 0.2304 \\
\hline \multirow{2}{*}{$\begin{array}{c}\text { FSSP } \\
\text { parameters }\end{array}$} & \multicolumn{15}{|c|}{$1000 \mathrm{rpm}$ (rotational speed) } \\
\hline & \multicolumn{5}{|c|}{$0.1 \mathrm{~mm}$ (penetration depth) } & \multicolumn{5}{|c|}{$0.15 \mathrm{~mm}$ (penetration depth) } & \multicolumn{5}{|c|}{$0.2 \mathrm{~mm}$ (penetration depth) } \\
\hline Temperature & $25^{\circ} \mathrm{C}$ & $100^{\circ} \mathrm{C}$ & $200^{\circ} \mathrm{C}$ & $400^{\circ} \mathrm{C}$ & $500^{\circ} \mathrm{C}$ & $25^{\circ} \mathrm{C}$ & $100^{\circ} \mathrm{C}$ & $200^{\circ} \mathrm{C}$ & $400^{\circ} \mathrm{C}$ & $500^{\circ} \mathrm{C}$ & $25^{\circ} \mathrm{C}$ & $100^{\circ} \mathrm{C}$ & $200^{\circ} \mathrm{C}$ & $400^{\circ} \mathrm{C}$ & $500^{\circ} \mathrm{C}$ \\
\hline $\begin{array}{c}\text { Wearing } \\
\text { capacity, } \mathrm{mm}^{3}\end{array}$ & 0.0707 & 0.0321 & 0.0386 & 0.0616 & 0.3395 & 0.0473 & 0.0234 & 0.0446 & 0.0612 & 0.3746 & 0.0393 & 0.0187 & 0.0273 & 0.0422 & 0.1617 \\
\hline FSSP & \multicolumn{15}{|c|}{$1200 \mathrm{rpm}$ (rotational speed) } \\
\hline parameters & \multicolumn{5}{|c|}{$0.1 \mathrm{~mm}$ (penetration depth) } & \multicolumn{5}{|c|}{$0.15 \mathrm{~mm}$ (penetration depth) } & \multicolumn{5}{|c|}{$0.2 \mathrm{~mm}$ (penetration depth) } \\
\hline Temperature & $25^{\circ} \mathrm{C}$ & $100^{\circ} \mathrm{C}$ & $200^{\circ} \mathrm{C}$ & $400^{\circ} \mathrm{C}$ & $500^{\circ} \mathrm{C}$ & $25^{\circ} \mathrm{C}$ & $100^{\circ} \mathrm{C}$ & $200^{\circ} \mathrm{C}$ & $400^{\circ} \mathrm{C}$ & $500^{\circ} \mathrm{C}$ & $25^{\circ} \mathrm{C}$ & $100^{\circ} \mathrm{C}$ & $200^{\circ} \mathrm{C}$ & $400^{\circ} \mathrm{C}$ & $500^{\circ} \mathrm{C}$ \\
\hline $\begin{array}{c}\text { Wearing } \\
\text { capacity, } \mathrm{mm}^{3}\end{array}$ & 0.0502 & 0.0267 & 0.0265 & 0.0576 & 0.3289 & 0.0310 & 0.0217 & 0.0410 & 0.0607 & 0.2929 & 0.0260 & 0.0046 & 0.0153 & 0.0418 & 0.1559 \\
\hline
\end{tabular}



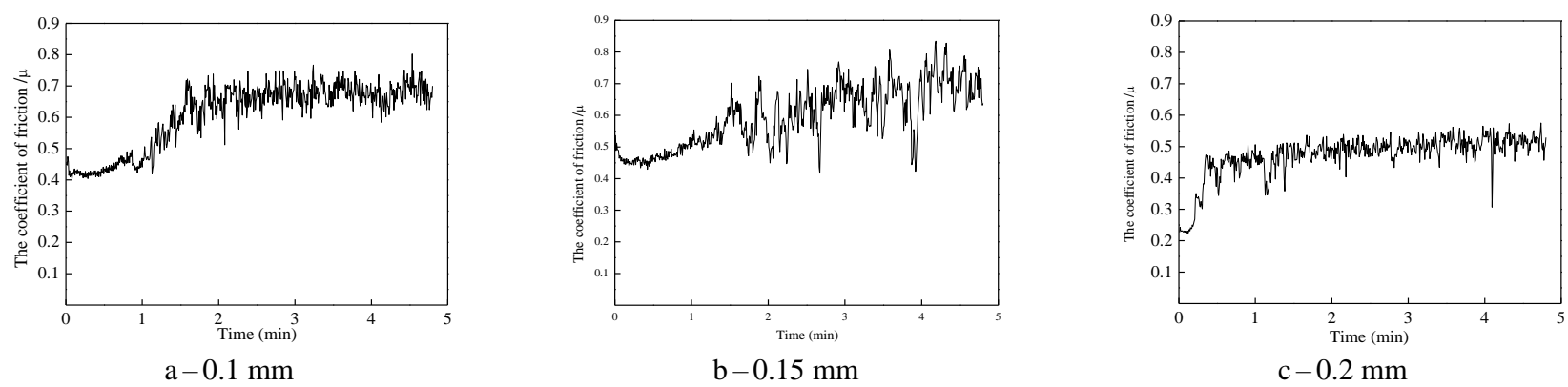

Fig. 5. The friction coefficient of the modified surface measured at room temperature and the rotation speed of $800 \mathrm{rpm}$ for different penetration depths
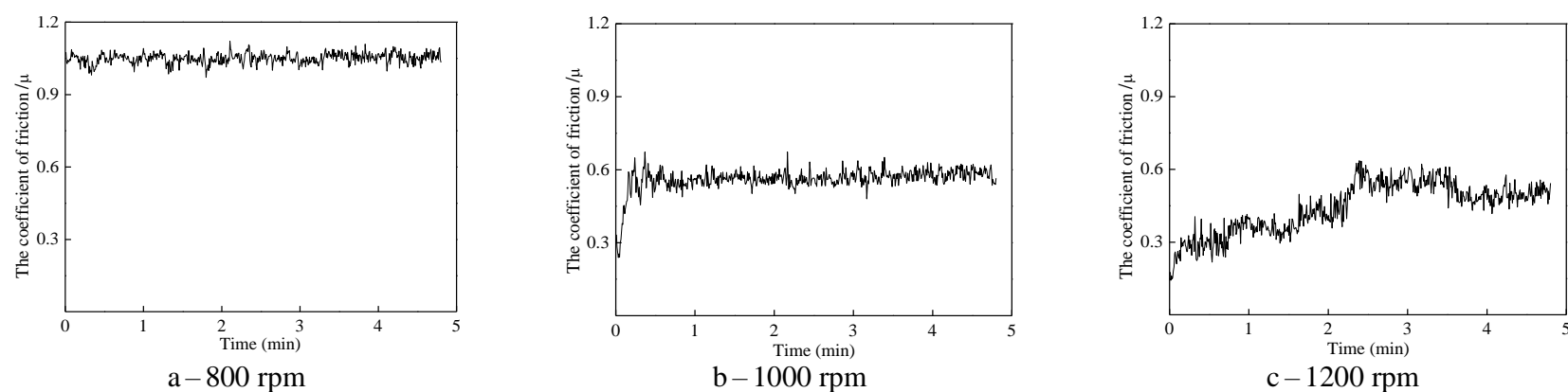

Fig. 6. The friction coefficient of the modified surface at the wear test temperature of $100{ }^{\circ} \mathrm{C}$ and the penetration depths of $0.1 \mathrm{~mm}$ for different rotation rates

The reason is that in this phase with the further increase of temperature, grain growth causes a lower hardness, thus reducing the wear capacity [16].

In order to further analyze wear under different parameters, the friction coefficients of the specimens are showed in Fig. 5 and Fig. 6. It can be seen in Fig. 5 that the friction coefficient of the modified surface decreases with an increase in the penetration depths of the stirring tool when the speed of rotation is $800 \mathrm{rpm}$ at $25^{\circ} \mathrm{C}$. It can also be observed in Fig. 6 that the friction coefficient of the modified surface decreases as the rotation rate increases for the penetration depth of $0.1 \mathrm{~mm}$ at $100^{\circ} \mathrm{C}$. These results are consistent with those in Table 2.

In Fig. 7, large cracks and flaked off areas can be observed on the specimen surface for the rotation speed of $800 \mathrm{rpm}$ and the penetration depth of $0.1 \mathrm{~mm}$, indicating the serious wear of the specimen surface, which is likely due to the extrusion flow. The specimen subjected to FSSP with a penetration depth of $0.15 \mathrm{~mm}$ also shows traces of extrusion flow on the surface. However, surface wear of the specimen is not obvious for the penetration depth of $0.2 \mathrm{~mm}$. It can be deduced that the steel ball has already glided on the surface during the test because the surface is very smooth. These observations indicate that the surface hardness increases as the penetration depth of the stirring tool increases, thus improving the surface wear performance. From Fig. 8, it can be seen that the surface wear resistance is better than the ones described above for wear tests done at $100{ }^{\circ} \mathrm{C}$. However, the flowing traces of extrusion are still apparent on the surface of the specimen subjected to FSSP at $800 \mathrm{rpm}$. The surfaces of specimens subjected to FSSP at higher rotational speeds appear smoother, which is consistent with the results in Table 2, Fig. 5 and Fig. 6. No matter what kind of FSSP parameters, the obtained modified layer thickness is more than $0.1 \mathrm{~mm}$, which is greater than that of shot peening (a few microns). Therefore, the FSSP technique is superior to the shot peening.

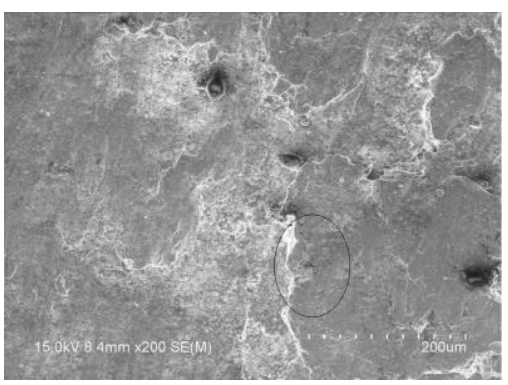

$\mathrm{a}-0.1 \mathrm{~mm}$

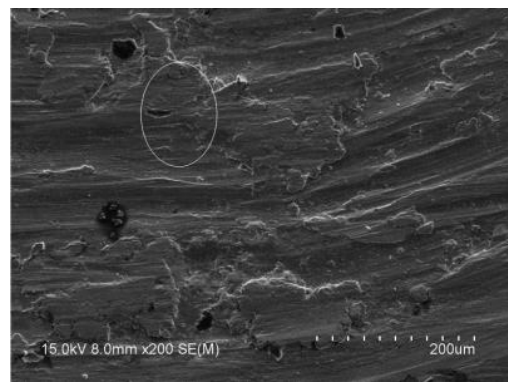

$\mathrm{b}-0.15 \mathrm{~mm}$

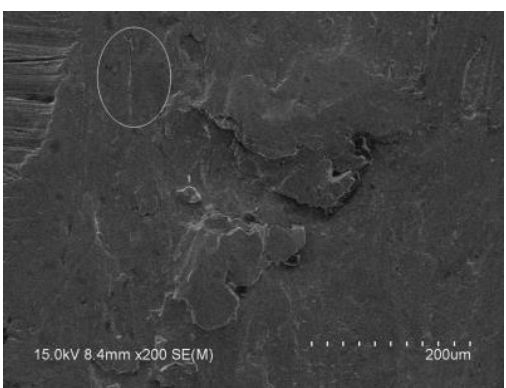

$\mathrm{c}-0.2 \mathrm{~mm}$

Fig. 7. SEM images of the modified surface after the wear tests at room temperature and the rotation rate of $800 \mathrm{rpm}$ for different penetration depths 


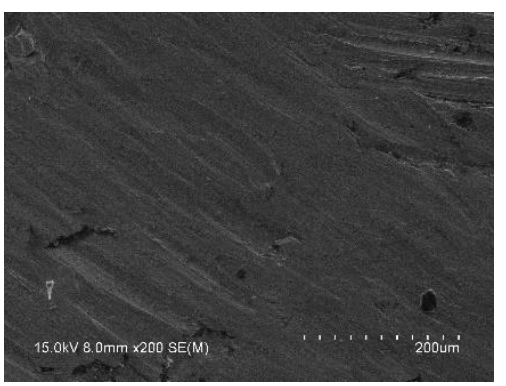

$\mathrm{a}-800 \mathrm{rpm}$

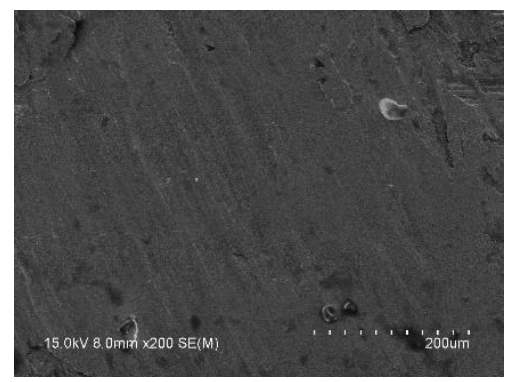

b-1000 rpm

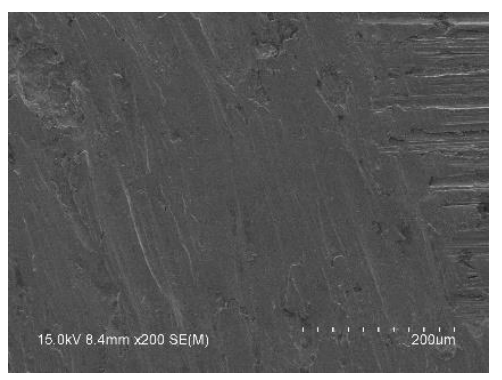

$\mathrm{c}-1200 \mathrm{rpm}$

Fig. 8. SEM images of the modified surface after the wear tests at the temperature of $100{ }^{\circ} \mathrm{C}$ and the penetration depth of $0.1 \mathrm{~mm}$ for different rotation rates.

\section{CONCLUSIONS}

In summary, FSSP has been used in surface modification of H62 copper alloy, and the effect of processing parameters and temperature on sliding wear of the alloy surface is studied. The experimental results show that (i) the specimen hardness initially increases as the wear test temperature increases, then decreases as the temperature further increases for fixed rotation rate and penetration depth, (ii) The specimen wearing capacity decreases as the rotation rate of the stirring tool increases for fixed penetration depth and wear test temperature, (iii) The specimen wearing capacity decreases as the penetration depth increases for constant rotation rate and wear test temperature. Therefore, in order to obtain better performance of H62 copper alloy surface, the optimum FSSP parameters are rotational speed $1200 \mathrm{rpm}$, temperature $100{ }^{\circ} \mathrm{C}$ and penetration depth $0.2 \mathrm{~mm}$, respectively. So FSSP should be a promising technique for modifying H62 copper alloy, which can be widely applied in shipbuilding in the future.

\section{Acknowledgments}

This study is supported by Remanufacturing surface engineering technology research center of Anhui Polytechnic University of China (Grant No. RMSE201606) and the excellent young talents fund key project of the Anhui Higher Education Institutions of China (Grant No. 2013SQRL089ZD).

\section{REFERENCES}

1. Wu, J.L., Wang, K.S., Zhou, L.H., Wang, W. Development of Friction Stir Processing Hot Working Technology 39 (9) 2010: pp. $150-153$.

2. Lin, Y.Y., Liu, C.L., Wu, B.B., Huang, W.J. The Progress of Friction Stir Processing Employed in the Surface Treatment of Aluminum Alloys (I) Material Review 27 (8) 2013: pp.139-144.

3. Gao, X., Zhang, Z., Wang, K.S., Wang, W. The Latest Research Situation of Superplasticity of Magnesium Alloys Prepared by Friction Stir Processing Materials Review 28 (3) 2014: pp. $138-142$.

4. Huang, C.P., Ke, L.M., Xing, L., Liu, G.P. Research Progress and Prospect of Friction Stir Processing Rare Metal Materials and Engineering $40(1)$ 2011: pp. 183-188.

5. Zhao, J.H., Ma, A.B., Jiang, J.H., Song, D., He, Q., Zhou, X. Development Progress of Friction Stir
Processing for $\mathrm{Mg}$ Alloys Material Review

$27(9)$ 2013: pp. $138-142$.

6. Xue, P., Xiao, B., Ma, Z. Microstructure and Mechanical Properties of Friction Stir Processed Ultrafine-Grained and Nanostructured Cu-Al Alloy Acta Metallurgica Sinica 50 (2) 2014: pp. $245-251$. https://doi.org/10.3724/SP.J.1037.2013.00661

7. Li, J.Y., Zhuo, Y. Effect of Friction Stir Processing on the Microstructure of Cast Aluminum Alloy Applied to Plunger Journal of Aeronautical Materials $33(3)$ 2013: pp. $58-63$.

https://doi.org/10.3969/j.issn.1005-5053.2013.3.011

8. Zeng, R.C., Chen, J., Dietzel, W., Zettler, R., F. dos Santos, J., Nascimento, M.L., Karl, U.K. Corrosion of Friction Stir Welded Magnesium Alloy AM50 Corrosion Science 51 (8) 2009: pp. $1738-1746$.

https://doi.org/10.1016/j.corsci.2009.04.031

9. Woo, W., Choo, H., Brown, D.W., Liaw, P.K., Feng, Z. Texture Variation and its Influence on the Tensile Behavior of a Friction -Stir Processed Magnesium Alloy Scripta Materialia 54 (11) 2006: pp. 1859-1864. https://doi.org/10.1016/j.scriptamat.2006.02.019

10. Xin, R., Li, B., Li, L., Liu, Q. Influence of Texture on Corrosion Rate of AZ31 Mg Alloy in $3.5 \mathrm{wt} \% \mathrm{NaCl}$ Materials \& Design 32 (8/9) 2011: pp. 4548-4552. https://doi.org/10.1016/j.matdes.2011.04.031

11. Wang, K.D., Chang, L.L., Wang, Y.N., Huang, Z.Q. Preparation of Mg-AZ31 Based Composites with Ti Particles by Friction Stir Processing The Chinese Journal of Nonferrous Metals 19 (3) 2009: pp. 418-423.

12. Zhang, D.T., Xiong, F., Zhang, W.W., Qiu, C., Zhang, W. Superplasticity of AZ31 Magnesium Alloy Prepared by Friction Stir Processing Transactions of Nonferrous Metals Society of China 21 (9) 2011: pp. 1911-1916. https://doi.org/10.1016/S1003-6326(11)60949-7

13. Fang, Y.., Zhou, X.P., Xu, F. Microstructural Evolution of Aluminum $\mathrm{Al}_{2} \mathrm{O}_{3}-\mathrm{TiB}_{2}$ Coating Produced by Friction Stirring Processing Special Casting \& Nonferrous Alloys 35 (6) 2015: pp. $618-621$. https://doi.org/10.15980/j.tzzz.2015.06.016

14. Wang, W., Wang, K.S., Guo, Q., Wu, N. Effect of Friction Stir Processing on Microstructure and Mechanical Properties of Cast AZ31 Magnesium Alloy Rare Metal Materials and Engineering 41 (9) 2012: pp. $1522-1526$. https://doi.org/10.1016/S1875-5372(13)60004-1

15. Chai, F., Zhang, D.T., Li, Y.Y. Effects of Heat Treatment on Microstructure and Mechanical Properties of AZ91 Magnesium Alloy Prepared by Friction Stir Processing The Chinese Journal of Nonferrous Metals 24 (12) 2014: pp. 2951-2960.

16. Li, J.Y., Liu, T., Guo, Y.W. High-Temperature Friction and Wear Properties of Friction Stir Processed Aluminum Matrix Composites Journal of Materials Engineering 43 (6) 2015: pp. $21-25$.

https://doi.org/10.11868/j.issn.1001-4381.2015.06.004 